\title{
Uptake of HIV testing in Burkina Faso: an assessment of individual and community- level determinants
}

\author{
Fati Kirakoya-Samadoulougou ${ }^{1 *}$, Kévin Jean ${ }^{2,3,4}$ and Mathieu Maheu-Giroux ${ }^{5}$ (D)
}

\begin{abstract}
Background: Previous studies have highlighted a range of individual determinants associated with HIV testing but few have assessed the role of contextual factors. The objective of this paper is to examine the influence of both individual and community-level determinants of HIV testing uptake in Burkina Faso.

Methods: Using nationally representative cross-sectional data from the 2010 Demographic and Health Survey, the determinants of lifetime HIV testing were examined for sexually active women $(n=14,656)$ and men $(n=5680)$ using modified Poisson regression models.

Results: One third of women (36\%; 95\% Confidence Interval (CI): 33-37\%) reported having ever been tested for HIV compared to a quarter of men (26\%; 95\% Cl: 24-27\%). For both genders, age, education, religious affiliation, household wealth, employment, media exposure, sexual behaviors, and HIV knowledge were associated with HIV testing. After adjustment, women living in communities where the following characteristics were higher than the median were more likely to report uptake of HIV testing: knowledge of where to access testing (Prevalence Ratio [PR] $=1.41 ; 95 \%$ Cl: 1.34-1.48), willing to buy food from an infected vendor ( $P R=2.06 ; 95 \% \mathrm{Cl}: 1.31-3.24)$, highest wealth quintiles $(\mathrm{PR}=1.18 ; 95 \% \mathrm{Cl}: 1.10-1.27)$, not working year-round ( $\mathrm{PR}=0.90 ; 95 \% \mathrm{Cl}: 0.84-0.96)$, and high media exposure $(\mathrm{PR}=1.11 ; 95 \% \mathrm{Cl}: 1.03-1.19)$. Men living in communities where the proportion of respondents were more educated $(\mathrm{PR}=1.23 ; 95 \% \mathrm{Cl}: 1.07-1.41)$ than the median were more likely to be tested.
\end{abstract}

Conclusions: This study shed light on potential mechanisms through which HIV testing could be increased in Burkina Faso. Both individual and contextual factors should be considered to design effective strategies for scaling-up HIV testing.

Keywords: HIV/AIDS, Contextual determinants, Human immunodeficiency virus, Multilevel models, Voluntary counselling and testing, West Africa

\section{Background}

HIV testing uptake is a key component of UNAIDS' newly adopted strategic framework. This framework calls for 90\% of people living with HIV (PLWH) being aware of their status (diagnosed), $90 \%$ of those diagnosed receiving treatment, and $90 \%$ of those receiving treatment being virally suppressed by 2020 (i.e., the $90-90-90$ objective) [1]. Voluntary counseling and testing (VCT) services for HIV represents the main entry point for prevention and

\footnotetext{
*Correspondence: fati.kirakoya@ulb.ac.be

${ }^{1}$ Centre de Recherche en Epidémiologie, Biostatistiques et Recherche Clinique, École de Santé Publique, Université Libre de Bruxelles, Brussels, Belgium

Full list of author information is available at the end of the article
}

care [2], and testing is considered one of the most costeffective ways to decrease HIV transmission [3, 4]. However, across sub-Saharan African countries, high proportions of PLWH are still unaware of their status, with large within-country variations [5]. Important HIV testing scale-up efforts, and subsequent rapid linkage to care [6], are thus needed to reach UNAIDS' objectives [7].

Expanding HIV testing requires a fine understanding of the individual and contextual variables that can act as barriers or facilitators to its uptake. Some individual predictors of HIV testing uptake, including wealth and education, have been consistently identified across sub-Saharan Africa [8-15]. On the other hand, factors such 
as sexual behaviors, and knowledge and attitudes toward HIV/AIDS have been found to be more variable across gender, as well as social and epidemiological settings [9, 16-21]. The health of individuals and their behaviors are shaped not only by individual factors, but also by the social environment's structure in which they live [22, 23]. An analysis of the importance of contextual factors on health outcomes could allow for a better understanding of the complex linkage between individual and contextual determinants of HIV testing uptake and, ultimately, lead to innovative community level interventions [24]. A previous study from eight African countries (not including Burkina Faso) highlighted the association between HIV testing uptake and community-level demographic, economic, and behavioral determinants [25]. However, the study only examined testing uptake among married men and efforts to assess community-level predictors of HIV testing have been limited [18].

HIV seroprevalence in Burkina Faso was estimated in 2010 at $1.2 \%$ and $0.8 \%$ among women and men, respectively [26]. Substantial regional variations were observed, ranging from $0.2 \%$ in the Plateau Central to $2.0 \%$ in Central. Nearly $60 \%$ of PLWH in Burkina Faso reported having never been tested for HIV [26], highlighting an important gap to reach UNAIDS's targets. The government of Burkina Faso - with international donors and many non-governmental organizations - have recently introduced and implemented programs to increase testing [27]. In this context, improving our understanding of individual and contextual barriers to HIV testing could contribute to its scale-up.

This study aims to examine individual and community determinants associated with lifetime HIV testing in Burkina Faso using a nationally representative sample of Burkinabè men and women. Understanding HIV testing uptake in relation to community characteristics, over and above individual factors, may provide new insights into the dynamics of HIV testing and help the national HIV program to more efficiently allocate their resources.

\section{Methods}

Data

This study uses data collected during the 2010 Burkina Faso Demographic and Health Survey (DHS), the first nationally-representative survey in Burkina Faso to collect information on previous HIV testing among both women and men. The survey protocol has been published elsewhere [26]. Briefly, the survey used a stratified, two-stage cluster sampling design. The country was stratified into rural and urban areas. Among each stratum, the first stage consisted of a random sample of clusters (primary sampling unit, PSU) using sampling probabilities proportional to the number of households in the cluster. Clusters were established by a general population and housing census conducted in 1996 (the average cluster populations were 1000 and 1200 in rural and urban areas, respectively). The second stage involved the systematic sampling of households from the selected clusters. A nationally representative sample of 14,957 households was thus obtained. All women aged 15 to 49 years were eligible to be interviewed. For men, a sub-sample of half of the selected households was randomly selected, from which all men aged 15 to 59 were eligible to be interviewed. Hereafter, the term community refers to all respondents living within the same geographical environment, corresponding to the PSU of the survey.

\section{Measures}

The main outcome for this study was the participants' self-reports of having ever been tested for HIV. Our independent variables were individual-level or communitylevel characteristics.

Individual variables covering socio-demographical, economical and behavioral dimensions, as well as knowledge and attitudes toward HIV/AIDS, were considered in the analyses. Socio-demographic covariates included: age, education, marital status, religion, occupational status, media exposure, location of residence (urban/rural), and an asset-based index of wealth [28]. The number of children ever born was also included for women. Sexual behavior was measured by self-reported lifetime number of sexual partners. HIV/AIDS knowledge was assessed by creating an index of correct responses to five (for men) and nine (for women) questions related to HIV transmission. Those sets of questions were summarized using principal component analysis, where the first axis explained $34 \%$ and $32 \%$ of the variance for women and men, respectively. This first axis was used to create a three-category index of HIV knowledge. Stigma towards PLWH was proxied using a set of four questions included in the DHS questionnaires: 1) willingness to share a relative's HIV infection status, 2) willingness to care for an infected relative, 3) belief that a female teacher infected with HIV should teach, and 4) willingness to buy food from an HIV infected vendor. This choice of independent variables was guided by prior research on HIV testing in sub-Saharan Africa countries [18, 25].

The main explanatory community-level variables of interest were: HIV prevalence, knowledge of HIV testing service, HIV/AIDS knowledge, HIV-related stigma (percentage of respondents with accepting attitudes towards people living with AIDS), and community socio-demographic characteristics (proportion of respondents who are at least high-school educated in the community, proportion of households belonging to the poorest quintiles of wealth, and proportion of individuals reporting low media exposure). Consideration of these variables was based 
on their potential to be modified and their known or hypothesized association with HIV testing $[22,25]$.

Community-level variables were aggregated from individual responses pertaining to individuals of the same sex and the same PSU (except for HIV prevalence which was aggregated at the regional level due to low number of cases). To avoid endogeneity problems related to the double inclusion of variables in the model - first at the individual-level and again at the aggregate-level community-level variables were calculated by excluding an individual's own response from the numerator and denominator of the aggregate-level variables. Indicators from each of the community-level determinants of HIV testing uptake were dichotomized using the median as a cut-off point. The stigma question regarding willingness to care for an infected relative was not considered at the community level because preliminary analyses showed that, for both women and men, the communities had low levels of stigma with small between-community variations that were not deemed qualitatively important.

\section{Statistical analysis}

For descriptive statistics at the individual and community levels, estimates accounted for the complex survey design using the sampling weights provided by DHS [29]. Prevalence ratios (PR) were obtained using a modified Poisson regression model that used Generalized Estimating Equation to take into account clustering of observations and perform the unbiased variance estimation [30, 31]. We did not adjust for survey weighting in the regressions. Univariate and multivariable analyses of individual-level covariates were first conducted. A complete case analysis was used and missing observations for women $(n=385)$ and men $(n=100)$ were disregarded. This was followed by multilevel models integrating the community-level variables. All multilevel models were adjusted for the following individuallevel covariates: age, education, number of children ever born (for women only), marital status, religion, wealth index, place of residence, media exposure, HIV knowledge, lifetime number of sexual partners, and the four personal stigma questions. Two multilevel models were fitted for both gender. The first multilevel model adjusted for individual-level variables and each of the main community-level determinants hypothesized to be related to the community variation in HIV testing separately: 2010 HIV prevalence, knowledge about VCT service, HIV/AIDS knowledge and HIV related stigma (model 1). The second multilevel model is fully adjusted for all individual-level and community-level variables enumerated above (model 2). Analyses were restricted to participants reporting having ever had sexual intercourse. All analyses were stratified by gender because attitudes toward HIV testing are likely to vary between women and men [32, 33]. Statistical analyses were performed using the $\mathrm{R}$ statistical software and the "geepack" package was used to fit the regression models [34].

\section{Results}

The sample of the 2010 Burkina Faso DHS consisted of 14,536 households, among 14,957 identified ones (421 households were unoccupied), and 17,087 women and 7307 men completed interviews. The participants' response rate was $98.4 \%$ for women and $97.3 \%$ for men. Inferences are thus based on the analyses of 14,373 women and 5680 men who reported having had sexual intercourse and without missing observations.

\section{Characteristics of the study population}

The sociodemographic characteristics of the study population are presented in Table 1. About half of the male participants were aged 35 years or older whereas only a third of female respondents were in this age group. About two thirds of respondents had no schooling and pproximatively $90 \%$ of women and $80 \%$ of men were married or living in a union. More than half were Muslims and two thirds lived in rural areas.

Among men and women, three-quarters of participants knew where they could get an HIV test (Table 2). Men were more educated, had higher level of media exposure, and higher HIV/AIDS knowledge than women. Additionally, men were more likely to have views that stigmatized HIV/AIDS than women (21\% vs. $9 \%$ expressed stigmatizing views to all four stigma-related questions) but few individuals had no stigmatizing views on all questions ( $7 \%$ and $6 \%$ of women and men, respectively).

\section{HIV testing uptake}

The proportion of women reporting having ever been tested for HIV was 35.6\% (95\% Confidence Interval [CI]: $32.9-37.4 \%$ ) while this proportion was $10 \%$ lower for men (25.6\%; 95\% CI: 24.2-26.6\%). Among women having ever been tested, $90.8 \%$ have had an HIV test as part of an antenatal care visit. HIV testing differed greatly geographically and was highest for both genders in the department of Central Region, where the capital Ouagadougou is located, at $61.9 \%$ for women and $46.6 \%$ for men (Figs. 1a, b). Lowest uptake of HIV testing was found in in the Sahel for women (16.4\%) and the Boucle $d u$ Mouhoun departments for men (13.9\%).

\section{Individual-level determinants of HIV testing uptake}

For both genders, uptake of HIV testing was associated with age, education, religious affiliation, household wealth index, being employed year-round, media exposure, number of lifetime sexual partners, and level of HIV knowledge (Table 3). The probability of having been tested 
Table 1 Socio-demographic characteristics of women and men participated in the Burkina Faso 2010 Demographic and Health Survey

\begin{tabular}{llll}
\hline Variables & \multicolumn{2}{l}{ Women } & \\
$\quad$ Proportion (\%) & & $N \quad$ Proportion (\%)
\end{tabular}

\begin{tabular}{lllll}
\hline $\begin{array}{l}\text { Age groups } \\
15-24\end{array}$ & 4403 & 30.3 & 1072 & 18.4 \\
$25-34$ & 5441 & 36.9 & 1791 & 31.4 \\
$\geq 35$ & 4914 & 32.9 & 2917 & 50.2 \\
Education & & & & \\
No school & 11,393 & 78.0 & 3722 & 65.6 \\
Primary & 1877 & 12.2 & 1076 & 18.5 \\
Secondary/higher & 1488 & 9.9 & 982 & 15.9
\end{tabular}

Number of children ever born

$\begin{array}{lll}0 & 1655 & 11.3 \\ 1-2 & 4052 & 27.3 \\ 3+ & 9051 & 61.4\end{array}$

Marital status

Married/in union 13,236

Single $\quad 1522 \quad 9.4$

Religion

Muslim

Christian

$8961 \quad 62.5$

$4330 \quad 28.6$

Animist/others

1426

8.6

Missing

$41 \quad 0.2$

Wealth index

Poorest

$2475 \quad 17.7$

$2747 \quad 19.3$

$2900 \quad 19.6$

$4528 \quad 79.5$

$1252 \quad 20.5$

Poor

Middle

Richer

Richest

$3160 \quad 20.4$

$3476 \quad 23.1$

Place of residence

\begin{tabular}{lllll} 
Urban & 4385 & 25.2 & 1967 & 29.2 \\
Rural & 10,373 & 74.8 & 3813 & 70.8 \\
$\begin{array}{l}\text { Working year-round } \\
\text { Yes }\end{array}$ & & & & \\
No & 3081 & 20.0 & 2133 & 36.8 \\
Missing & 11,632 & 79.7 & 3633 & 62.9 \\
Media exposure & 45 & 0.3 & 14 & 0.3 \\
Low (0-1) & 6165 & 42.2 & 998 & 18.3 \\
Middle (2-3) & 6271 & 42.1 & 3053 & 53.3 \\
High (4-6) & 2258 & 15.4 & 1715 & 28.2 \\
Missing & 64 & 0.4 & 14 & 0.2 \\
\hline
\end{tabular}

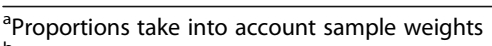

${ }^{b}$ Exposure to mass media was measured through a composite index of three survey items that assessed whether the respondent reads newspapers or magazines, listens to the radio, or watches television. The additive scale is split into a three-level categorical variable: low media exposure (score of $0-1$ ), medium media exposure (2-3), and high media exposure (4-6) was highest among women aged 15-24 and men aged 25-34 years. Having non-stigmatizing views on PLWH was associated with HIV testing uptake but this was not consistent for all stigma-related questions. For women, the number of children ever born was significantly associated with HIV testing.

\section{Community-level determinants of HIV testing uptake}

Table 4 presents results of the community-level determinants of HIV testing. For model 1, community-level determinants are adjusted only for selected individuallevel variables. On the other hand, model 2 is fully adjusted for individual and all community-level determinants listed in Table 4. Results from this fully adjusted model (model 2) suggested that women were significantly more likely to report testing in communities where a larger percentage of respondents knew the location of a VCT service, where views towards buying food from HIV positive vendors were less stigmatizing, where the proportion of respondents in the highest wealth quintile was higher, and in communities with the highest media exposure. Furthermore, women residing in community where the proportion of respondents not working year-round was higher than the median were $10 \%$ less likely to report having ever been tested. For men, few community determinants reached statistical significance for both model 1 and 2 . Men were more likely to report previous testing in communities where respondents were more educated.

\section{Discussion}

Using nationally representative data of sexually active women and men from Burkina Faso, we observed low levels of HIV testing uptake in 2010 with only a third of women and a quarter of men reporting having ever been tested for HIV. We identified several determinants of HIV testing uptake acting at individual and community levels, and their effect often varied by gender. Individual factors associated with HIV testing uptake included socio-demographic, economic, behavioral factors as well as knowledge and attitudes related to HIV. Communitylevel variables associated with HIV testing uptake were mostly related to education, wealth, occupational status, media exposure, and stigma.

Our study identified various individual correlates of HIV testing uptake. As previously documented, we observed among both men and women that testing uptake increased with educational level and wealth $[13,25,35,36]$. Similarly, high HIV-related knowledge and access to broader information channels, through media exposure, was associated with HIV testing [35-39]. These results highlight the importance of providing health education to both women and men while deploying targeted efforts to reach populations with low uptake of HIV testing. Some of the barriers 
Table 2 Knowledge of access to HIV testing, HIV knowledge, sex behaviors, and HIV stigma in women and men of Burkina Faso, 2010

\begin{tabular}{|c|c|c|c|c|c|}
\hline \multirow[t]{2}{*}{ Variables } & \multirow[b]{2}{*}{ N } & \multicolumn{2}{|l|}{ Women } & \multirow{2}{*}{$\frac{\text { Men }}{\text { Proportion (\%) }}$} & \\
\hline & & $\overline{\text { Proportion (\%) }}{ }^{\mathrm{a}}$ & $N$ & & \\
\hline \multicolumn{6}{|l|}{ Access/HIV knowledge } \\
\hline \multirow[t]{3}{*}{ Know a place to get tested } & No & 3345 & 24.3 & 1295 & 24.6 \\
\hline & Yes & 11,400 & 75.6 & 4481 & 75.3 \\
\hline & Missing & 13 & 0.1 & 4 & 0.1 \\
\hline \multirow[t]{4}{*}{ HIV knowledge score } & Low & 4888 & 34.2 & 1731 & 31.8 \\
\hline & Medium & 4881 & 34.6 & 1588 & 26.8 \\
\hline & High & 4867 & 30.4 & 2440 & 40.9 \\
\hline & Missing & 122 & 0.8 & 21 & 0.4 \\
\hline \multicolumn{6}{|l|}{ Sexual behavior } \\
\hline \multirow[t]{4}{*}{ Lifetime number of sexual partners } & 1 & 11,026 & 75.4 & 1169 & 21.4 \\
\hline & 2 & 2812 & 18.7 & 1454 & 26.0 \\
\hline & 3 or more & 904 & 5.8 & 3121 & 51.9 \\
\hline & Missing & 16 & 0.1 & 36 & 0.7 \\
\hline \multicolumn{6}{|l|}{ Personal stigma } \\
\hline \multirow{3}{*}{$\begin{array}{l}\text { If a relative would become HIV positive, } \\
\text { willing to share his/her infection status }\end{array}$} & No (stigma) & 10,894 & 73.9 & 3193 & 57.6 \\
\hline & Yes & 3860 & 26.1 & 2587 & 42.4 \\
\hline & Missing & 4 & 0.0 & 0 & 0.0 \\
\hline \multirow{3}{*}{$\begin{array}{l}\text { Willing to care for an HIV positive relative } \\
\text { in their own house }\end{array}$} & No (stigma) & 2314 & 16.5 & 473 & 9.3 \\
\hline & Yes & 12,443 & 83.5 & 5307 & 90.7 \\
\hline & Missing & 1 & 0.0 & 0 & 0.0 \\
\hline \multirow{3}{*}{$\begin{array}{l}\text { Believes that an HIV positive female teacher } \\
\text { (without symptoms) should teach }\end{array}$} & No (stigma) & 5466 & 38.9 & 1917 & 35.4 \\
\hline & Yes & 9292 & 61.1 & 3862 & 64.4 \\
\hline & Missing & 0 & 0.0 & 1 & 0.0 \\
\hline \multirow[t]{3}{*}{ Willing to buy food from an HIV positive vendor } & No (stigma) & 9402 & 64.8 & 3078 & 56.2 \\
\hline & Yes & 5355 & 35.2 & 2694 & 43.6 \\
\hline & Missing & 1 & 0.0 & 8 & 0.1 \\
\hline
\end{tabular}

aproportions take into account sampling weights

${ }^{\mathrm{b}}$ The five (men) and nine (women) questions entering the HIV knowledge index are: people can protect themselves from contracting HIV by (1) using condoms; (2) having sex only with one faithful, uninfected partner; (3) people knowing that mosquitoes can't transmit HIV and (4) that it cannot be transmitted by sharing food with an HIV-infected person; (5) a healthy looking person can have the AIDS virus; and, for women only, (6) people who report that HIV can be transmitted from mother to child during pregnancy, (7) delivery, and (8) through breastfeeding; and (9) know drugs to avoid AIDS transmission to baby during delivery and breastfeeding

to HIV testing uptake that we identified in this study may be related to the HIV testing offer modalities, however. For example, lower testing levels among participants living in rural areas may be related to lower accessibility of HIV testing sites in these regions.

The present study expands upon previous literature by providing evidence of gendered patterns of association between community determinants and HIV testing. Our results suggest that tested women were more likely to live in communities with high access to testing resources/facilities, where women are wealthier, and with better media exposure. For men, uptake of VCT was higher for those living in communities with larger proportions of respondents with secondary/higher education.

We observed that uptake of VCT was generally higher among individuals with less stigmatizing views. Decision-making about HIV testing are often linked to an individual's social network influences and addressing HIV-related stigma could improve community norms about testing. The recent HPTN-043 ACCEPT clusterrandomized trial demonstrated how addressing HIV-related community norms may translate into lower HIV-related stigma and increase uptake of HIV testing [40, 41]. This is especially relevant for Burkina Faso where levels of stigma 


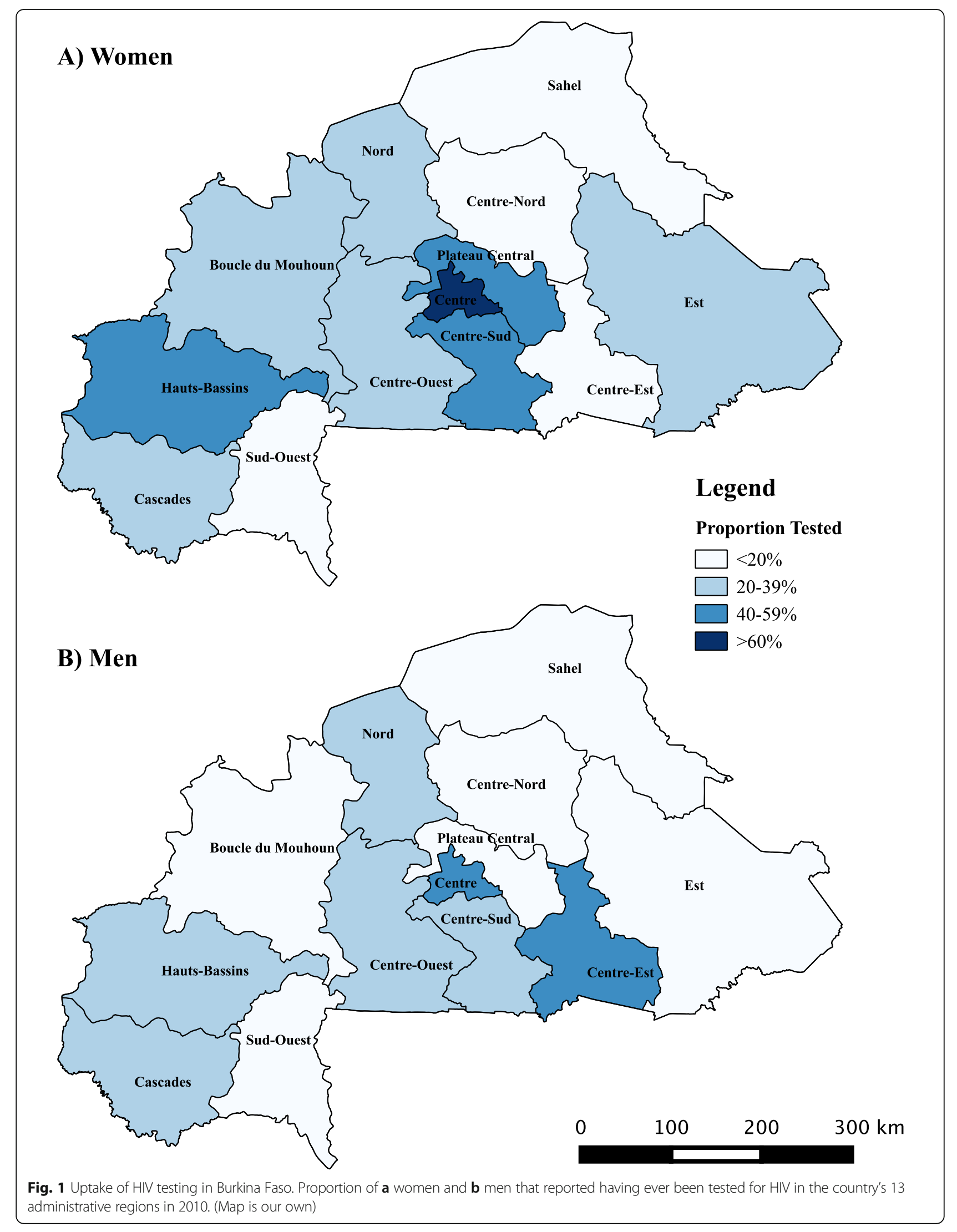


Table 3 Univariate and multivariable analyses of individual-level determinants of HIV testing uptake, stratified by gender

\begin{tabular}{|c|c|c|c|c|c|}
\hline \multirow{3}{*}{\multicolumn{2}{|c|}{ Variables }} & \multicolumn{2}{|c|}{ Women $(N=14,373)$} & \multicolumn{2}{|l|}{ Men $(N=5680)$} \\
\hline & & \multirow{2}{*}{$\begin{array}{l}\text { Univariate } \\
\mathrm{PR}^{\mathrm{a}}(95 \% \mathrm{Cl})\end{array}$} & \multirow{2}{*}{$\begin{array}{l}\text { Multivariable } \\
\operatorname{PR}^{\text {a }}(95 \% \mathrm{Cl})\end{array}$} & \multirow{2}{*}{$\begin{array}{l}\text { Univariate } \\
\mathrm{PR}^{\mathrm{a}}(95 \% \mathrm{Cl})\end{array}$} & \multirow{2}{*}{$\begin{array}{l}\text { Multivariable } \\
\text { PR }^{a}(95 \% \text { Cl) }\end{array}$} \\
\hline & & & & & \\
\hline \multicolumn{6}{|c|}{ Socio-demographic } \\
\hline \multicolumn{6}{|c|}{ Age groups } \\
\hline & $15-24$ & Referent & Referent & Referent & Referent \\
\hline & $25-34$ & $1.06(1.01-1.11)$ & $0.87(0.83-0.92)$ & $1.21(1.07-1.35)$ & $1.20(1.06-1.35)$ \\
\hline & $>35$ & $0.69(0.65-0.74)$ & $0.61(0.57-0.66)$ & $0.80(0.71-0.90)$ & $0.99(0.86-1.14)$ \\
\hline \multicolumn{6}{|c|}{ Education } \\
\hline & No school & Referent & Referent & Referent & Referent \\
\hline & Primary & $1.80(1.70-1.90)$ & $1.16(1.10-1.23)$ & $2.22(1.96-2.51)$ & 1. 35 (1.18-1.54) \\
\hline & Secondary/higher & $2.53(2.42-2.65)$ & $1.29(1.21-1.37)$ & $4.83(4.39-5.31)$ & 2. $01(1.76-2.30)$ \\
\hline \multicolumn{6}{|c|}{ Number of children ever born } \\
\hline & 0 & Referent & Referent & Not applicable & \\
\hline & $1-2$ & $1.33(1.23-1.43)$ & $1.63(1.51-1.75)$ & & \\
\hline & $3+$ & $0.93(0.86-1.00)$ & $1.78(1.63-1.94)$ & & \\
\hline \multicolumn{6}{|c|}{ Marital status } \\
\hline & In Union & Referent & Referent & Referent & Referent \\
\hline & Single & $1.24(1.17-1.32)$ & $0.95(0.89-1.01)$ & $1.35(1.23-1.49)$ & $0.95(0.86-1.06)$ \\
\hline \multicolumn{6}{|l|}{ Religion } \\
\hline & Muslim & Referent & Referent & Referent & Referent \\
\hline & Christian & $1.28(1.22-1.34)$ & $1.09(1.05-1.14)$ & $1.49(1.36-1.62)$ & $1.11(1.03-1.20)$ \\
\hline & Animist/others & $0.72(0.64-0.80)$ & $0.99(0.89-1.11)$ & $0.49(0.38-0.62)$ & $0.79(0.63-1.00)$ \\
\hline \multicolumn{6}{|c|}{ Wealth index } \\
\hline & Poorest & Referent & Referent & Referent & Referent \\
\hline & Poorer & $1.33(1.19-1.48)$ & $1.26(1.13-1.40)$ & $1.37(1.04-1.81)$ & $1.12(0.85-1.47)$ \\
\hline & Middle & $1.48(1.33-1.64)$ & $1.30(1.18-1.44)$ & $2.02(1.56-2.62)$ & $1.50(1.16-1.94)$ \\
\hline & Richer & $1.88(1.70-2.08)$ & $1.44(1.31-1.59)$ & $3.23(2.54-4.12)$ & $1.91(1.48-2.46)$ \\
\hline & Richest & $3.28(3.00-3.60)$ & $1.57(1.41-1.76)$ & $6.69(5.33-8.40)$ & $1.90(1.45-2.49)$ \\
\hline \multicolumn{6}{|c|}{ Place of residence } \\
\hline & Urban & Referent & Referent & Referent & Referent \\
\hline & Rural & $0.44(0.42-0.46)$ & $0.75(0.71-0.80)$ & $0.34(0.31-0.37)$ & $0.90(0.80-1.01)$ \\
\hline \multicolumn{6}{|c|}{ Working year-round } \\
\hline & Yes & Referent & Referent & Referent & Referent \\
\hline & No & $0.62(0.59-0.65)$ & $0.90(0.86-0.94)$ & $0.48(0.44-0.53)$ & $0.86(0.79-0.94)$ \\
\hline \multicolumn{6}{|c|}{ Media exposure } \\
\hline & Low & Referent & Referent & Referent & Referent \\
\hline & Middle & $1.39(1.31-1.47)$ & $1.13(1.07-1.20)$ & $1.66(1.37-2.03)$ & $1.23(1.01-1.49)$ \\
\hline & High & $2.52(2.38-2.67)$ & $1.21(1.13-1.30)$ & $4.9(4.06-5.93)$ & $1.49(1.20-1.84)$ \\
\hline \multicolumn{6}{|c|}{ HIV knowledge } \\
\hline & $\operatorname{Low}(1-3)$ & Referent & Referent & Referent & Referent \\
\hline & Medium (4-5) & $1.56(1.46-1.66)$ & $1.31(1.23-1.39)$ & $1.55(1.32-1.82)$ & $1.18(1.00-1.38)$ \\
\hline & High (6-7) & $2.10(1.98-2.23)$ & $1.45(1.37-1.54)$ & $3.22(2.81-3.68)$ & $1.29(1.12-1.49)$ \\
\hline
\end{tabular}


Table 3 Univariate and multivariable analyses of individual-level determinants of HIV testing uptake, stratified by gender (Continued)

Sexual behavior

Lifetime sexual partners

$\begin{array}{ll}1 & \text { Referent } \\ 2 & \mathbf{1 . 2 5}(\mathbf{1 . 1 9 - 1 . 3 2 )} \\ 3 \text { and }+ & \mathbf{1 . 7 1 ( 1 . 6 0 - 1 . 8 2 )}\end{array}$

Referent

1.09 (1.04-1.14)

1.18 (1.11-1.25)

Referent

3 and +

Stigma-related questions

Willing to share a relative's HIV infection status

$\begin{array}{ll}\text { No (stigma) } & \text { Referent } \\ \text { Yes } & 0.94(0.89-0.99)\end{array}$

$0.94(0.89-0.99)$

Referent

$0.93(0.89-0.98)$

Referent

1.33 (1.22-1.45)

Referent

Willing to care for an infected relative

$\begin{array}{ll}\text { No (stigma) } & \text { Referent } \\ \text { Yes } & 1.94(1.78-2.12)\end{array}$

1.94 (1.78-2.12)

Referent

Referent

$2.68(2.06-3.48)$

Referent

1.24 (1.14-1.36)

No (stigma)

Referent

1.91 (1.80-2.01)

Yes

Willing to buy food from an infected vendor

$\begin{array}{ll}\text { No (stigma) } & \text { Referent } \\ \text { Yes } & \mathbf{2 . 1 3} \mathbf{( 2 . 0 4 - 2 . 2 3 )}\end{array}$

$2.13(2.04-2.23)$
Referent

$1.16(1.09-1.24)$

Referent

Referent

$2.97(2.60-3.40)$

1.32 (1.14-1.54)

Referent

$1.36(1.29-1.43)$
Referent

Referent

2.97 (2.68-3.29)
$1.38(1.23-1.56)$

a

Table 4 Multivariable analysis of community-level determinants of HIV testing uptake in Burkina Faso women and men

\begin{tabular}{|c|c|c|c|c|}
\hline \multirow[t]{3}{*}{ Variable0073 } & \multicolumn{2}{|c|}{ Women $(N=14,373)$} & \multicolumn{2}{|l|}{ Men $(N=5680)$} \\
\hline & Model $1^{\mathrm{a}}$ & Model $2^{\mathrm{a}}$ & Model $1^{\mathrm{a}}$ & Model $2^{\mathrm{a}}$ \\
\hline & PR $(95 \% \mathrm{Cl})$ & PR $(95 \%$ Cl) & PR $(95 \%$ Cl) & PR $(95 \%$ Cl) \\
\hline Community with higher HIV prevalence & $0.97(0.93-1.02)$ & $1.00(0.96-1.05)$ & $1.06(0.97-1.16)$ & $1.06(0.97-1.16)$ \\
\hline $\begin{array}{l}\text { Community with higher knowledge } \\
\text { of place to get tested }\end{array}$ & $1.43(1.36-1.50)$ & $1.41(1.34-1.48)$ & $1.01(0.92-1.10)$ & $1.01(0.93-1.11)$ \\
\hline Community with lower HIV/AIDS knowledge & $0.96(0.91-1.00)$ & $1.01(0.96-1.06)$ & $1.03(0.94-1.13)$ & $1.04(0.95-1.14)$ \\
\hline $\begin{array}{l}\text { Community more willing to share a } \\
\text { relative's infection HIV status }\end{array}$ & $1.02(0.98-1.06)$ & $1.01(0.97-1.06)$ & $0.97(0.89-1.05)$ & $0.97(0.89-1.06)$ \\
\hline $\begin{array}{l}\text { Community believing female teacher } \\
\text { infected with HIV should teach }\end{array}$ & $1.18(1.07-1.30)$ & $1.01(0.92-1.12)$ & $0.84(0.68-1.04)$ & $0.81(0.64-1.04)$ \\
\hline $\begin{array}{l}\text { Community more willing to buy food } \\
\text { from an infected vendor }\end{array}$ & $2.17(1.39-3.36)$ & $2.06(1.31-3.24)$ & $0.83(0.55-1.24)$ & $0.91(0.57-1.43)$ \\
\hline Community with more educated respondents & $1.17(1.10-1.25)$ & $1.01(0.94-1.08)$ & $1.24(1.09-1.41)$ & $1.23(1.07-1.41)$ \\
\hline $\begin{array}{l}\text { Community with higher proportion of } \\
\text { respondents not working year-round }\end{array}$ & $0.82(0.77-0.87)$ & $0.90(0.84-0.96)$ & $0.90(0.79-1.03)$ & $0.95(0.82-1.10)$ \\
\hline $\begin{array}{l}\text { Community with more respondents in the } \\
\text { highest wealth quintile }\end{array}$ & $1.29(1.21-1.38)$ & $1.18(1.10-1.27)$ & $1.10(0.95-1.26)$ & $1.00(0.85-1.17)$ \\
\hline Community with higher media exposure & $1.22(1.15-1.30)$ & $1.11(1.03-1.19)$ & $1.12(0.97-1.28)$ & $1.06(0.91-1.22)$ \\
\hline
\end{tabular}

Statistically significant results are bolded

PR Prevalence Ratio, 95\% Cl 95\% Confidence Interval

${ }^{a}$ Model 1 has each community variable included separately in the model and adjusted for the following individual-level determinants: age, education, number of children ever born (for women only), marital status, religion, wealth index, place of residence, media exposure, HIV knowledge, lifetime number of sexual partners, and personal stigma. Model 2 is fully adjusted for all variables listed in the table and the individual-level determinants adjusted for in Model 1 
were found to be high: only $7 \%$ of women and $5 \%$ of men expressed no stigmatizing attitudes about PLWH.

We acknowledge some limitations in this study. The measures used in this paper were self-reported and therefore susceptible to social desirability biases. The use of cross-sectional data also makes the temporal sequences between some covariates and testing uptake in this study unknowns. Furthermore, communities were defined based on PSU memberships. Because social networks do not necessarily follow the dimensions of a PSU, we might have under or overestimated effect size measures of the community-level determinants. Additionally, we were not able to account for the availability and proximity of health infrastructures, as well as the quality of their health services. Finally, female sex workers and men who have sex with men, key populations at high risk of HIV acquisition and transmission, could be underrepresented in population-based household surveys such as this one.

Strengths of this study included its large sample size and high response rate. To our knowledge, this study is the first to identify correlates of HIV testing uptake among a nationally-representative sample of the Burkinabè population. Furthermore, by aggregating data at the PSU level we examined community-level determinants while avoiding issues of ecological fallacy.

\section{Conclusions}

To reach UNAIDS' 90-90-90 target, HIV testing in Burkina Faso should be considerably scaled-up in the coming years. Among individuals who were found to be HIV positive in the 2010 seroprevalence survey, about $60 \%$ reported having never been tested for HIV. This points to a potentially important gap in the national response. Given that more than $50 \%$ of new HIV infection in Burkina Faso occur among stable couples [42], interventions to scale-up testing will need to focus on these partnerships. HIV testing interventions among members of key populations, such as female sex workers and men who have sex with men, also warrants further consideration [43-46]. To increase HIV testing uptake, several interventions and policies could be considered. First, accessibility to HIV diagnosis should be improved in rural areas with high HIV prevalence. Testing campaigns in particular have been shown to reach high population coverage and uptake. Furthermore, mobile HIV testing campaigns may be particularly effective in increasing HIV testing coverage in rural settings, among men, and young adults $[47,48]$. Socio-economic inequalities in HIV testing could be reduced by the implementation of specific testing modalities such as the systematic proposition of an HIV test by health care workers [12]. However, restricting the offer of HIV testing to health facilities would not be sufficient to increase HIV testing among populations having few contacts with healthcare providers, especially the adult male population [48]. Attempts to offer HIV testing outside health facilities may thus be an effective way to increase uptake [49]. Especially, self-testing for HIV may be a relevant option to be considered in contexts of high HIV-related stigma [50].

Reaching the undiagnosed PLWH in a timely manner is a crucial and necessary step for individuals to benefit from antiretroviral treatment and to sustainably reduce population-level HIV transmission [51, 52]. Implementing effective policies to address individual and communitylevel barriers to testing is required to achieve this objective.

\section{Abbreviations}

Cl: Confidence intervals; DHS: Demographic and Health Survey; HIV: Human immunodeficiency virus; PLWH: People living with HIV; PR: Prevalence ratios; PSU: Primary sampling unit; VCT: Voluntary counselling and testing

\section{Acknowledgments}

We thank the DHS Program for access to the Burkina Faso Demographic Health Survey's unrestricted data files. MMG's research is supported by the Bisby prize and a postdoctoral fellowship from the Canadian Institutes of Health Research.

\section{Funding}

This study did not receive funding.

\section{Availability of data and materials}

The dataset containing individual-level records are in the public domain and can be obtained from The DHS Program (http://dhsprogram.com//).

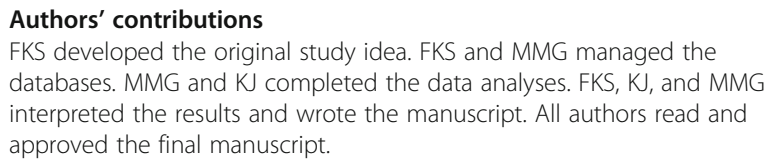
databases. MMG and KJ completed the data analyses. FKS, KJ, and MMG interpreted the results and wrote the manuscript. All authors read and approved the final manuscript.

\section{Competing interests}

The authors declare that they have no competing interests.

\section{Consent for publication}

Not applicable.

\section{Ethics approval and consent to participate}

The survey received ethical approval from the Internal Review Board of ICF International, in the USA, and from the Burkina Faso National Ethics Committee. Informed consent was obtained from all adult subjects or from their parents/guardian for minors.

\section{Publisher's Note}

Springer Nature remains neutral with regard to jurisdictional claims in published maps and institutional affiliations.

\section{Author details}

${ }^{1}$ Centre de Recherche en Epidémiologie, Biostatistiques et Recherche Clinique, École de Santé Publique, Université Libre de Bruxelles, Brussels, Belgium. ${ }^{2}$ Department of Infectious Disease Epidemiology, Imperial College London, St Mary's Hospital, London, UK. ${ }^{3}$ Laboratoire MESuRS (EA 4628), Conservatoire National des Arts et Métiers, Paris, France. ${ }^{4}$ Conservatoire National des Arts et Métiers, Unité PACRI, Institut Pasteur, Paris, France. ${ }^{5}$ Department of Epidemiology, Biostatistics, and Occupational Health, McGill University, Montréal, Canada. 
Received: 2 May 2016 Accepted: 12 May 2017 Published online: 22 May 2017

\section{References}

1. UNAIDS. 90-90-90: an ambitious treatment target to help end the AIDS epidemic. Geneva: Joint United Nations Programme on HIV/AIDS (UNAIDS); 2014. p. 33.

2. Fonner VA, Denison J, Kennedy CE, O'Reilly K, Sweat M. Voluntary counseling and testing (VCT) for changing HIV-related risk behavior in developing countries. Cochrane Database SystRev. 2012;9:CD001224.

3. Li J, Gilmour S, Zhang H, Koyanagi A, Shibuya K. The epidemiological impact and cost-effectiveness of HIV testing, antiretroviral treatment and harm reduction programs. AIDS. 2012;26(16):2069-78.

4. Penazzato M, Revill P, Prendergast AJ, Collins IJ, Walker S, Elyanu PJ, Sculpher M, Gibb DM. Early infant diagnosis of HIV infection in low-income and middle-income countries: does one size fit all? Lancet Infect Dis. 2014; 14(7):650-5.

5. Staveteig S, Wang S, Head S, Bradley S, Nybro E. Demographic patterns of HIV testing uptake in sub-Saharan Africa. In: DHS Comparative Reports No 30. Calverton: ICF International; 2013. p. 81.

6. Maheu-Giroux M, Tanser F, Boily MC, Pillay D, Joseph SA, Barnighausen T. Determinants of time from HIV infection to linkage-to-care in rural KwaZuluNatal, South Africa. AIDS. 2017;31(7):1017-24

7. Maheu-Giroux M, Vesga J, Diabaté S, Alary M, Baral S, Diouf D, Kouamé A, Boily M: Population-level impact of an accelerated HIV response plan to reach UNAIDS' 90-90- 90 target in Côte d'Ivoire: insights from mathematical modeling. PLoS Med (in press) 2017.

8. Bwambale FM, Ssali SN, Byaruhanga S, Kalyango JN, Karamagi CA. Voluntary HIV counselling and testing among men in rural western Uganda: implications for HIV prevention. BMC Public Health. 2008:8:263.

9. Peltzer K, Matseke G, Mzolo T, Majaja M. Determinants of knowledge of HIV status in South Africa: results from a population-based HIV survey. BMC Public Health. 2009;9:174

10. Mitchell S, Cockcroft A, Lamothe G, Andersson N. Equity in HIV testing: evidence from a cross-sectional study in ten Southern African countries. BMC Int Health Hum Rights. 2010;10:23.

11. Ziraba AK, Madise NJ, Kimani JK, Oti S, Mgomella G, Matilu M, Ezeh A. Determinants for HIV testing and counselling in Nairobi urban informal settlements. BMC Public Health. 2011:11:663.

12. Jean K, Anglaret X, Moh R, Lert F, Dray-Spira R. Barriers to HIV testing in Côte d'Ivoire: the role of individual characteristics and testing modalities. PLoS One. 2012;7(7):e41353.

13. Cremin I, Cauchemez S, Garnett GP, Gregson S. Patterns of uptake of HIV testing in sub-Saharan Africa in the pre-treatment era. Tropical Med Int Health. 2012;17(8):e26-37.

14. Lépine A, Terris-Prestholt F, Vickerman P. Determinants of HIV testing among Nigerian couples: a multilevel modelling approach. Health Policy Plan. 2015;30(5):579-92.

15. Brima N, Burns F, Fakoya I, Kargbo B, Conteh S, Copas A. Factors Associated with HIV Prevalence and HIV Testing in Sierra Leone: Findings from the 2008 Demographic Health Survey. PLoS One. 2015;10(10):e0137055.

16. Young SD, Hlavka Z, Modiba P, Gray G, Van Rooyen H, Richter L, Szekeres G, Coates T. HIV-Related Stigma, Social Norms, and HIV Testing in Soweto and Vulindlela, South Africa: National Institutes of Mental Health Project Accept (HPTN 043). J Acquir Immune Defic Syndr. 2010;55(5):620-4.

17. Tenkorang EY, Owusu GA. Correlates of HIV testing among women in Ghana: some evidence from the Demographic and Health Surveys. AIDS Care. 2010;22(3):296-307.

18. Koku EF. Desire for, and uptake of HIV tests by Ghanaian women: the relevance of community level stigma. J Community Health. 2011;36(2):289-99.

19. Venkatesh KK, Madiba P, De Bruyn G, Lurie MN, Coates TJ, Gray GE. Who gets tested for HIV in a South African urban township? Implications for test and treat and gender-based prevention interventions. J Acquir Immune Defic Syndr. 2011;56(2):151-65.

20. Leta TH, Sandøy IF, Fylkesnes K. Factors affecting voluntary HIV counselling and testing among men in Ethiopia: a cross-sectional survey. BMC Public Health. 2012:12:438.

21. Matovu JKB, Denison J, Wanyenze RK, Ssekasanvu J, Makumbi F, Ovuga E, McGrath N, Serwadda D. Trends in HIV counseling and testing uptake among married individuals in Rakai, Uganda. BMC Public Health. 2013;13:618.
22. UNAIDS. A conceptual framework and basis for action: HIV/AIDS stigma and discrimination. Geneva: Joint United Nations Programme on HIV/AIDS (UNAIDS); 2002.

23. Denison JA, McCauley AP, Dunnett-Dagg WA, Lungu N, Sweat MD. The HIV testing experiences of adolescents in Ndola, Zambia: do families and friends matter? AIDS Care. 2008:20(1):101-5.

24. Pickett KE, Pearl M. Multilevel analyses of neighbourhood socioeconomic context and health outcomes: a critical review. J Epidemiol Community Health. 2001;55(2):111-22.

25. Stephenson R, Miriam EK, Winter A. Community influences on married men's uptake of HIV testing in eight African countries. AIDS Behav. 2013; 17(7):2352-66.

26. INSD, ICF International. Enquête Démographique et de Santé et à Indicateurs Multiples du Burkina Faso 2010. In. Calverton: Institut National de la Statistique et de la Démographie and ICF International; 2012.

27. Somé JF, Desclaux A, Ky-Zerbo O, Lougué M, Kéré S, Obermeyer C. Simaga F: [Campaigns for HIV testing, an effective strategy for universal access to prevention and treatment? The experience of Burkina Faso]. Med Sante Trop. 2014;24(1):73-9.

28. Rutstein SO, Johnson K. DHS Comparative Reports. The DHS Wealth Index Calverton: ORC Macro; 2004.

29. Macro International Inc. Sampling Manual. In: DHS-III Basic Documentation No 6. Calverton. Maryland, U.S.A. 1996.

30. Zou G. A modified poisson regression approach to prospective studies with binary data. Am J Epidemiol. 2004;159(7):702-6.

31. Yelland LN, Salter AB, Ryan P. Performance of the modified Poisson regression approach for estimating relative risks from clustered prospective data. Am J Epidemiol. 2011;174(8):984-92.

32. Obermeyer CM, Sankara A, Bastien V, Parsons M. Gender and HIV testing in Burkina Faso: an exploratory study. Soc Sci Med. 2009;69(6):877-84.

33. Obermeyer CM, Osborn M. The utilization of testing and counseling for HIV a review of the social and behavioral evidence. Am J Public Health. 2007; 97(10):1762-74.

34. Højsgaard S, Halekoh U, Yan J. The R Package geepack for Generalized Estimating Equations. J Stat Softw. 2006;15(2):1-11

35. Obermeyer CM, Neuman M, Hardon A, Desclaux A, Wanyenze R, Ky-Zerbo $\mathrm{O}$, Cherutich P, Namakhoma I. Socio-economic determinants of HIV testing and counselling: a comparative study in four African countries. Tropical Med Int Health. 2013;18(9):1110-8.

36. Paulin $H N$, Blevins $M$, Koethe $J R$, Hinton $N$, Vaz LME, Vergara $A E$, Mukolo A, Ndatimana E, Moon TD, Vermund SH, et al. HIV testing service awareness and service uptake among female heads of household in rural Mozambique: results from a province-wide survey. BMC Public Health. 2015;15:132

37. Mbago MCY. Socio-demographic correlates of desire for HIV testing in Tanzania. Sex Health. 2004;1(1):13-21.

38. Sherr L, Lopman B, Kakowa M, Dube S, Chawira G, Nyamukapa C, Oberzaucher N, Cremin I, Gregson S. Voluntary counselling and testing: uptake, impact on sexual behaviour, and HIV incidence in a rural Zimbabwean cohort. AIDS (London, England). 2007;21(7):851-60.

39. Ayenew A, Leykun A, Colebunders R, Deribew A. Predictors of HIV testing among patients with tuberculosis in North West Ethiopia: a case-control study. PLoS One. 2010;5(3):e9702.

40. Maman S, Hv R, Stankard P, Chingono A, Muravha T, Ntogwisangu J, Phakathi Z, Srirak N, Morin FS, Team at NPAs. NIMH Project Accept (HPTN 043): Results from In-Depth Interviews with a Longitudinal Cohort of Community Members. PLoS One. 2014;9(1):e87091.

41. Coates TJ, Kulich M, Celentano DD, Zelaya CE, Chariyalertsak S, Chingono A, Gray G, Mbwambo JKK, Morin SF, Richter L, et al. Effect of community-based voluntary counselling and testing on HIV incidence and social and behavioural outcomes (NIMH Project Accept; HPTN 043): a clusterrandomised trial. Lancet Glob Health. 2014:2(5):e267-77.

42. UNAIDS. New HIV infections by mode of transmission in West Africa: a multicountry analysis. Dakar: UNAIDS Regional Support Team for West and Centra Africa. Joint United Nations Programme on HIV/AIDS (UNAIDS); 2010.

43. Goodman SH, Grosso AL, Ketende SC, Ouedraogo GH, Kouanda S, Ky-Zerbo O, Samadoulougou C, Baral S. Examining the Correlates of Sexually Transmitted Infection Testing Among Men Who Have Sex With Men in Ouagadougou and Bobo-Dioulasso Burkina Faso. Sex Transm Dis. 2016;43(5):302-9.

44. Maheu-Giroux M, Vesga JF, Diabate S, Alary M, Baral S, Diouf D, Abo K, Boily MC. Changing dynamics of HIV transmission in Cote d'Ivoire: modeling who 
acquired and transmitted infections and estimating the impact of past HIV interventions (1976-2015). J Acquir Immune Defic Syndr. 2017.

45. Maheu-Giroux M, Vesga JF, Diabate S, Alary M, Boily MC. Modeling the HIV Epidemic in Côte d'Ivoire: Impact of Past Interventions. AIDS Res Hum Retrovir. 2016;32:300.

46. Tanser F, de Oliveira T, Maheu-Giroux M, Bärnighausen T. Concentrated HIV subepidemics in generalized epidemic settings. Curr Opin HIV AIDS. 2014; 9(2):115-25.

47. Labhardt ND, Motlomelo M, Cerutti B, Pfeiffer K, Kamele M, Hobbins MA, Ehmer J. Home-Based Versus Mobile Clinic HIV Testing and Counseling in Rural Lesotho: A Cluster-Randomized Trial. PLoS Med. 2014;11(12):e1001768.

48. Sharma M, Ying R, Tarr G, Barnabas R. Systematic review and meta-analysis of community and facility-based HIV testing to address linkage to care gaps in sub-Saharan Africa. Nature. 2015;528(7580):S77-85.

49. Suthar AB, Ford N, Bachanas PJ, Wong VJ, Rajan JS, Saltzman AK, Ajose O, Fakoya AO, Granich RM, Negussie EK, et al. Towards universal voluntary HIV testing and counselling: a systematic review and meta-analysis of community-based approaches. PLoS Med. 2013;10(8):e1001496.

50. Krause J, Subklew-Sehume F, Kenyon C, Colebunders R. Acceptability of HIV self-testing: a systematic literature review. BMC Public Health. 2013;13:735.

51. Cohen MS, Chen YQ, McCauley M, Gamble T, Hosseinipour MC, Kumarasamy N, Hakim JG, Kumwenda J, Grinsztejn B, Pilotto JH, et al. Prevention of HIV-1 infection with early antiretroviral therapy. N Engl J Med. 2011;365(6):493-505.

52. Bor J, Herbst AJ, Newell ML, Bärnighausen T. Increases in adult life expectancy in rural South Africa: valuing the scale-up of HIV treatment. Science. 2013;339(6122):961-5.

\section{Submit your next manuscript to BioMed Central and we will help you at every step:}

- We accept pre-submission inquiries

- Our selector tool helps you to find the most relevant journal

- We provide round the clock customer support

- Convenient online submission

- Thorough peer review

- Inclusion in PubMed and all major indexing services

- Maximum visibility for your research

Submit your manuscript at www.biomedcentral.com/submit 